\title{
Photodegradation kinetics of formaldehyde using light sources of UVA, UVC and UVLED in the presence of composed silver titanium oxide photocatalyst
}

\author{
Je-Lueng Shie ${ }^{\mathrm{a}, *}$, Chia-Hsiang Lee ${ }^{\mathrm{b}}$, Chyow-San Chiou ${ }^{\mathrm{a}}$, \\ Chang-Tong Chang ${ }^{\mathrm{a}}$, Chia-Chi Chang ${ }^{\mathrm{b}}$, Ching-Yuan Chang ${ }^{\mathrm{b}}$ \\ ${ }^{a}$ Department of Environmental Engineering, National I-Lan University, 1, Section 1, Shen-Lung Road, \\ I-Lan 260, Taiwan \\ ${ }^{\mathrm{b}}$ Graduate Institute of Environmental Engineering, National Taiwan University, 1, \\ Section 4, Roosevelt Road, Taipei 106, Taiwan
}

Received 29 September 2007; received in revised form 13 November 2007; accepted 13 November 2007

Available online 21 November 2007

\begin{abstract}
This study investigated the surface modification of photocatalyst and photodecomposition of formaldehyde from indoor pollution source. This study explored the feasibility of the application of the ultraviolet light emitting diode (UVLED) instead of the traditional ultraviolet (UV) lamp to treat the formaldehyde. The photocatalytic decomposition of formaldehyde at various initial concentrations was elucidated according to the Langmuir-Hinshelwood model. The reaction rate constant $(k)$ and adsorption equilibrium constant $\left(K_{\mathrm{L}}\right)$ over $0.334 \mathrm{~g}$ silver titanium oxide photocatalyst $\left(\mathrm{Ag} / \mathrm{TiO}_{2}\right)$ coated on glass sticks with $254 \mathrm{~nm}$ ultraviolet lamp (UVC), $365 \mathrm{~nm}$ ultraviolet lamp (UVA), and UVLED are 650 ppmv min ${ }^{-1}$ and $2 \times 10^{-4} \mathrm{ppmv}^{-1}, 500 \mathrm{ppmv}^{-1} \mathrm{~min}^{-1}$ and $1.04 \times 10^{-4} \mathrm{ppmv}^{-1}$, and $600 \mathrm{ppmv} \mathrm{min}^{-1}$ and $2.52 \times 10^{-5} \mathrm{ppmv}^{-1}$, respectively. A comparison of the simulation results with the experimental data was also made, indicating good agreement. The magnitudes of energy effectiveness $\left(E_{\mathrm{e}}\right)$ are in the order of UVLED $\left(0.6942 \mathrm{mg} \mathrm{kW}^{-1} \mathrm{~h}^{-1}\right)>\operatorname{UVA}\left(0.007 \mathrm{mg} \mathrm{kW}^{-1} \mathrm{~h}^{-1}\right)>\mathrm{UVC}\left(0.0053 \mathrm{mg} \mathrm{kW}^{-1} \mathrm{~h}^{-1}\right)$. The $E_{\mathrm{e}}$ of UVLED is 131 times larger than that of UVC. The UVLED can save a lot of energy in comparison with the traditional UV lamps. Thus, this study showed the feasible and potential use of UVLED in photocatalysis.
\end{abstract}

(C) 2007 Elsevier B.V. All rights reserved.

Keywords: Formaldehyde; Silver titanium oxide photocatalyst; Ultraviolet light emitting diode; Indoor pollution; Langmuir-Hinshelwood model

\section{Introduction}

Recently, photocatalysis has received enormous attention for pollution control and indoor air purification. It has the advantages of use of inexpensive photocatalyst $\left(\mathrm{TiO}_{2}\right)$, operating under room temperature and atmospheric pressure, and nearly complete oxidation of carbon and hydrogen containing pollutants into $\mathrm{CO}_{2}$ and $\mathrm{H}_{2} \mathrm{O}$ [1]. Studies related to photocatalysis including reaction kinetics [2], photocatalyst improvement [3], photocatalyst deactivation [4], reaction design [5-7], reaction mechanism [8] and pollutant mixture effects [9] have been extensively investigated. One of the major objectives for these studies

\footnotetext{
* Corresponding author. Tel.: +8863 9353563; fax: +88639353563.

E-mail address: jlshie@ niu.edu.tw (J.-L. Shie).
}

is the elimination of indoor air pollutants, for example, the destruction of formaldehyde. Studies have shown that a high conversion of formaldehyde can be obtained by photocatalysis [10]. Formaldehyde is an irritant and it is also classified as a carcinogen [11]. In recent years, formaldehyde emission is considered to be one of the major causes of sick building syndrome. The conditions are characterized by drowsiness, headache, sore throat and mental fatigue in many occupants of modern office buildings, shopping centers, schools and newly built houses [12]. Common indoor sources of formaldehyde are incense burning and building materials [13]. Therefore, it leads to a need for the development of air clean technology. The application and validity of photocatalysis on the removal of formaldehyde in indoor air has aroused great interest as noted above [10]. There are many other papers also examining the photocatalytic removal of formaldehyde [14-17]. However, no study has reported the 
photodegradation of formaldehyde via ultraviolet light emitting diode (UVLED) using silver-loaded titania photocatalysts $\left(\mathrm{Ag} / \mathrm{TiO}_{2}\right)$.

The UV-light irradiation plays a dramatic energy provider on the photodegradation of formaldehyde. The activity of the photocatalyst depends strongly on the light-illumination (energy per unit area) or the photon flux on the surface of the catalyst. UV lamp has been commonly used for the applications of photocatalysis. The types of light sources used include Xe arc (300-800 nm), Hg-arc [15,18-20] (1000 W/Oriel Co.; $100 \mathrm{~W}$, 125 W/Philips HPK; 125 W/Philips HPR), Hg-Xe (200 W/Oriel Co.) and black-light lamp [18,21-26] (6 W/GE, $100 \mathrm{~W} / \mathrm{UVP}$, 4 W/GE F4T5-BLB, 8 W/Sankyo Denki F8T8). The most significant difference is that more intermediates are evolved by using the germicidal source, such as UV light, than those by using the black light [27]. However the traditional UV lamp has disadvantages of a short life, instability of the output power and the hazardous materials from the emitted wastes. The application of UV should be handled with care because the UV emission from UV lamps contains harmful light to humans. On the contrary, UVLED has a longer life with low electricity consumption and a higher reliability. The simple structure of UVLED can make it easy to be applied as an alternative light source to the security systems such as the counterfeit detection. UV light can activate a photocatalyst to destruct the harmful indoor air substances. Therefore, UVLED combined with the $\mathrm{TiO}_{2}$ and $\mathrm{Ag} / \mathrm{TiO} \mathrm{O}_{2}$ photocatalyst is expected to make a significant contribution to the development of a compact and effective air purifier. Considering all such potential applications, the enormous markets for UVLED can be anticipated in the near future.

This study investigates the feasibility of the applications of the UVLED as the light source instead of the traditional UV lamps to treat the indoor air pollutant of formaldehyde. Formaldehyde is taken as a model compound, because it has the highest concentration among volatile organic compounds (VOCs) in the indoor air pollutants. The UVLED is more novel, and has lower power, electromotive force (emf) demand and price, while higher efficiency, life-span and security as compared to UV lamp. Also it does not generate heat. The photocatalyst used in this study was $\mathrm{Ag} / \mathrm{TiO}_{2}$ which was made by the incipient wet impregnation method, and then coated on the glass plates or sticks. To the best of our knowledge, no study has reported the use of UVLED as the light source on photodegradation of formaldehyde with the $\mathrm{TiO}_{2}$ or $\mathrm{Ag} / \mathrm{TiO}_{2}$ photocatalysts in indoor air purification.

\section{Experimental}

\subsection{Reagents and catalyst}

\subsubsection{Formaldehyde}

Formaldehyde of purity $37 \%$ was purchased from Hayashi Pure Chemical Ind. Co. Ltd., Japan. $0.55 \mu \mathrm{L}$ of formaldehyde was injected into the reactor. Right after, the formaldehyde was vaporized at $313 \mathrm{~K}$, and atmospheric pressure, producing a vapor containing $500 \mathrm{ppmv}$ formaldehyde.

\subsubsection{Catalyst}

$\mathrm{TiO}_{2}$ of Degussa P-25 was supplied by Degussa, used as received without any pretreatment for comparison. $\mathrm{Ag} / \mathrm{TiO}_{2}$ was prepared by the incipient wet impregnation with $\mathrm{AgNO}_{3}$ on $\mathrm{TiO}_{2}$. After being dried at $378 \mathrm{~K}$ in an oven, the catalysts were illuminated with the $254 \mathrm{~nm}$ UV lamp (UVC) for $24 \mathrm{~h}$ for the reduction of $\mathrm{Ag}^{+}$to $\mathrm{Ag}$. For coating purpose, the $\mathrm{TiO}_{2}$ and $\mathrm{Ag} / \mathrm{TiO}_{2}$ were suspended in solutions acetylacetone $(2,4-$ Pentanedione, Nacalai Tesque Inc., Kyoto, Japan) and Triton X-100 (Nacalai Tesque Inc., Kyoto, Japan). The commercial $\left(\mathrm{TiO}_{2}\right)$ and modified composed $\left(\mathrm{Ag} / \mathrm{TiO}_{2}\right)$ photocatalysts were then uniformly coated on the supports of glass plates or sticks. The wetted supports with film of coated catalysts were dried at $378 \mathrm{~K}$ in an oven and then calcined at $723 \mathrm{~K}$ for $0.5 \mathrm{~h}$. The nitrate ions existed in the first step of the incipient wet impregnation process of $\mathrm{TiO}_{2}$ with $\mathrm{AgNO}_{3}$, however, the $\mathrm{Ag} / \mathrm{TiO}$ 俩 were then suspended in the solutions with DI water, acetylacetone and Triton X-100 under the ratios of 27:1:1 in the follow step for the coating purpose. In this step, the nitrate ions dissolved into the solution and evaporated in the calcined process. The X-ray single crystal diffractometer (XRD) (Siemens Smart, Germany), scanning electron microscope (SEM) (Hitachi S-800, Japan), energy dispersive spectrometer (EDS) (S-2400, Hitachi, Japan) and Brunauer Emmett Teller (BET) surface measurement device (Model ASAP 2100, USA) were used for the characteristic analyses of $\mathrm{TiO}_{2}$ and $\mathrm{Ag} / \mathrm{TiO}_{2}$.

\subsection{Experimental}

\subsubsection{Photocatalytic reactor system}

The photocatalytic reactor system is shown in Fig. 1. A cylindrical Pyrex glass reactor of $1000 \mathrm{~mL}$ capacity was used as a reaction vessel in which a UV lamp was inserted as a light source. Various lamps were tested, including UVC (Philips

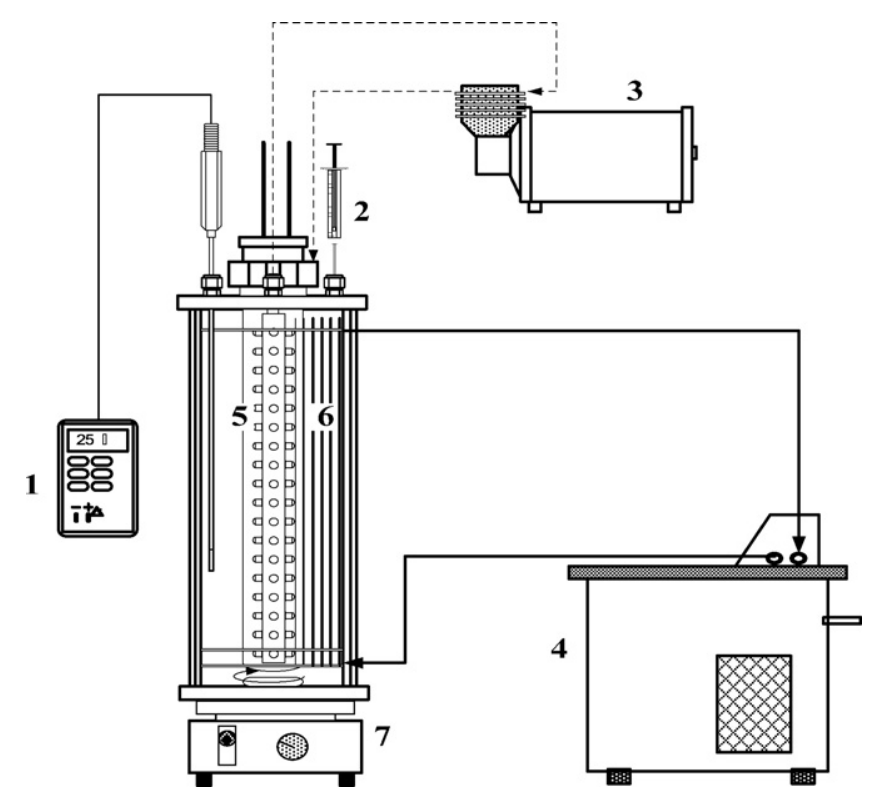

Fig. 1. Schematic diagram of apparatus for catalytic decomposition of formaldehyde: (1) thermometer; (2) sampling port; (3) cycling pump; (4) circulating bath; (5) light source; (6) catalytic support; (7) magnetic stirrer. 


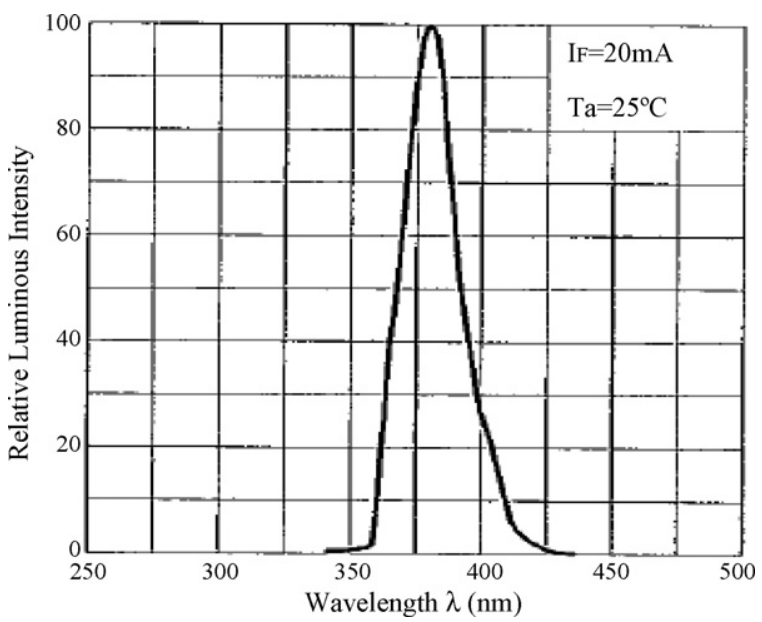

Fig. 2. Photon energy distribution spectrum profile of UVLED. $I_{\mathrm{F}}$ : DC forward current. $T_{\mathrm{a}}$ : ambient temperature.

TUV, $16 \mathrm{~W}$ ), $365 \mathrm{~nm}$ UV lamp (UVA) (Philips, $12 \mathrm{~W}$ ) and 30 or 40 UVLEDs ( $20 \mathrm{~mW}$ per UVLED, $\lambda=383 \mathrm{~nm}(\Delta \lambda=18 \mathrm{~nm}$, Fig. 2), TG Purple Hi LED E1L5M-4P0A2-01, Toyota Gosei Co. Ltd., Taiwan). The UV lamp was surrounded by a quartz glass tube to protect it preventing direct contact with formaldehyde. The top cover and bottom plates of the reactor were made from stainless steel 316 . Four glass plates $(200 \mathrm{~mm}$ $(L) \times 45 \mathrm{~mm}(W) \times 2 \mathrm{~mm}(D), 360 \mathrm{~cm}^{2}$ illuminated area) or 200 glass sticks $\left(1177.5 \mathrm{~cm}^{2}\right.$ (half illuminated area of total 200 glass sticks)), with outside surface were coated with $\mathrm{TiO}_{2}$ or $\mathrm{Ag} / \mathrm{TiO}_{2}$ $\left(0.14 \mathrm{mg} \mathrm{cm}^{-2}\right)$, were inserted into the vessel. After complete mixing using stirrer and cycling pump, the temperature of the vessel was kept at $303 \mathrm{~K}$ by constant temperature circulating bath (Model-B403, First Scientific, Taiwan) to avoid the temperature disturbance.

\subsubsection{Procedures and sampling}

The pure dry air was introduced for $30 \mathrm{~min}$ to push the residual gas in the reactor and $14.5 \mu \mathrm{L}$ DI water was injected to maintain 50\% relative humidity (RH). Then, formaldehyde was injected into the reactor. After sampling for measuring the initial concentration of formaldehyde, the reactor was kept in darkness for $1 \mathrm{~h}$ to allow the adsorption of formaldehyde onto $\mathrm{TiO}_{2}$ photocatalyst to approach the state of equilibrium. The light source (UVC, UVA or UVLED) was then turned on. The concentrations of formaldehyde were measured and the changes of temperatures were also monitored.

\subsubsection{Analysis}

A standard carbonyl sampler filled with an acidified 2,4dinitrophenylhydrazine (DNPH-silica, LpBNPH S10, Supelco, USA) was used to collect formaldehyde according to the USEPA TO-11 (NIEA A705.10T) method. The gas analyzing system is composed of a high performance liquid chromatography (HPLC) (Model 500, Viscotek, USA). The flow rate of sampling used to calculate the formaldehyde concentration is the average flow rates before and after the sampling. The gas sample was injected into adsorption column of DNPH. The DNPH-carbonyl derivative was extracted by acetonitrile (ACN) solution. The extract of derivative was measured via HPLC. The operating conditions of HPLC were set as follows: $516 \mathrm{C}-18$ reverse phase column $(250 \mathrm{~mm} \times 4.6 \mathrm{~mm}, 5 \mu \mathrm{m}$ i.d., Supelco, USA $)$, mobile phase of $\mathrm{CH}_{3} \mathrm{CN}$ :DI water $=50: 50$ (wt.), flow rate of $1 \mathrm{~mL} \mathrm{~min}{ }^{-1}$, wavelength of absorbance of detector of $360 \mathrm{~nm}$ and volume of loop of $100 \mu \mathrm{L}$. Quantitative analysis of gaseous products was conducted using the linear calibration response equations of standards. The equation was generated for each compound of gas standard using a minimum of five different concentrations with three replicates at each concentration. All correlation coefficients $\left(r^{2}\right)$ of linear calibration response curves exceed $99.7 \%$.

\section{Results and discussion}

\subsection{Characteristics of $\mathrm{TiO}_{2}$ and $\mathrm{Ag} / \mathrm{TiO} O_{2}$}

\subsubsection{SEM}

The SEM spectra were taken for the photocatalyst samples and are illustrated in Fig. 3. The sizes of $\mathrm{TiO}_{2}$ and $\mathrm{Ag} / \mathrm{TiO}_{2}$ are between $50-70$ and $50-60 \mathrm{~nm}$, respectively. The size did not change a lot after the incipient wet impregnation with $\mathrm{AgNO}_{3}$ on $\mathrm{TiO}_{2}$. The aggregated phenomena may be due to the electrostatic attraction. The silver particle cannot be detected by SEM due to the limited resolution of the microscope [28].

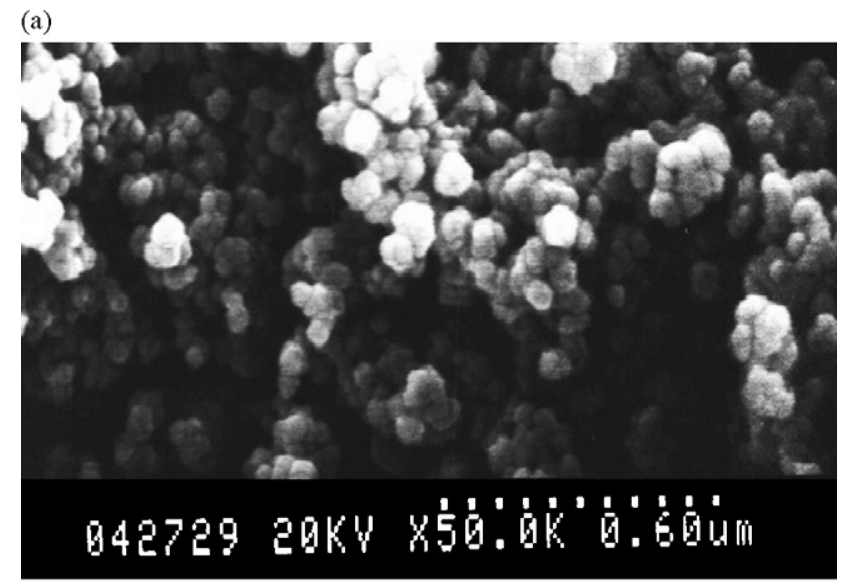

(b)

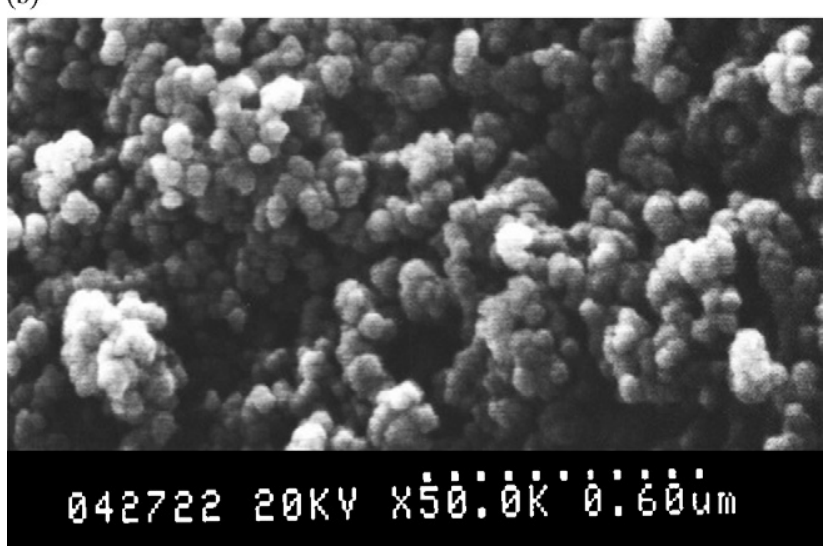

Fig. 3. Scanning electron micrographs of (a) $\mathrm{TiO}_{2}$ and (b) $\mathrm{Ag} / \mathrm{TiO}_{2}(50,000 \times)$ 


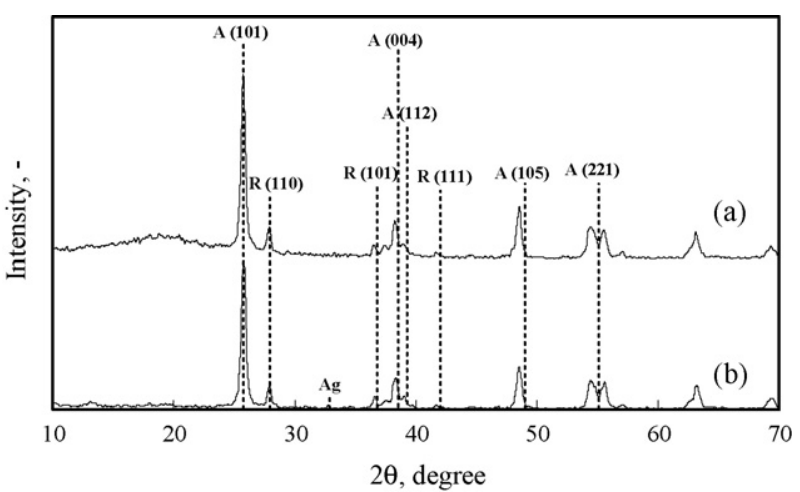

Fig. 4. XRD patterns of (a) $\mathrm{TiO}_{2}$ and (b) $\mathrm{Ag} / \mathrm{TiO}_{2}$.

\subsection{2. $X R D$}

Fig. 4 shows the XRD patterns of $\mathrm{TiO}_{2}$ and $\mathrm{Ag} / \mathrm{TiO}_{2}$. As compared with the database of Joint Committee on Powder Diffraction Standards (JCPDS), the crystal distribution of $\mathrm{TiO}_{2}$ (Degussa P-25) is composed of about $70 \%$ anatase and $30 \%$ rutile. It is well known that the energy band-gaps of anatase and rutile are 3.23 and $3.02 \mathrm{eV}$, respectively [27]. Due to the lower effective mass of electron, higher production rate of pair of electron-hole and lower recombination rate in anatase, the mobility of electrons in anatase is higher than that of rutile [29]. Therefore, for the photocatalytic oxidation (PCO) application, anatase is superior to rutile [27]. From Fig. 4(b), the reductions of $\mathrm{Ag}$ on $\mathrm{TiO}_{2}$ surface did not change the crystal distribution of $\mathrm{TiO}_{2}$. Nevertheless, a peak of $\mathrm{Ag}$ appeared in the diffractogram at the refraction angle of $2 \theta=34.5^{\circ}$ because Ag only deposited on the surface of $\mathrm{TiO}_{2}$ and still did not form the crystal. The average crystalline sizes of $\mathrm{TiO}_{2}$ and $\mathrm{Ag} / \mathrm{TiO}_{2}$ calculated by Scherrer equation are listed in Table 1.

\subsubsection{EDS}

Fig. 5(a) and (b) displays the EDS diagrams of $\mathrm{Ag} / \mathrm{TiO}_{2}$ and $\mathrm{TiO}_{2}$, respectively. Fig. 5(a) indicates that the weight percentages of $\mathrm{O}, \mathrm{Ti}$ and $\mathrm{Ag}$ in $\mathrm{Ag} / \mathrm{TiO}_{2}$ are 58.48, 39.91 and 1.6\%, respectively. The amount of Ag deposited was $1.6 \mathrm{wt} . \%(\mathrm{w} / \mathrm{w})$. For the comparison, the weight percentages of $\mathrm{O}$ and $\mathrm{Ti}$ of $\mathrm{TiO}_{2}$ listed in Fig. 5(b) are 63.33 and $36.67 \%$, respectively. From the results, the incipient wet impregnation process using $\mathrm{AgNO}_{3}$ solution followed by calcined process at $723 \mathrm{~K}$ for $0.5 \mathrm{~h}$ decreased the weight percentage of $\mathrm{O}$ from 63.33 to $58.48 \%$ and increased that of Ti from 36.67 to $39.91 \%$, respectively.

\subsubsection{BET surface area}

The BET surface areas of $\mathrm{TiO}_{2}$ and $\mathrm{Ag} / \mathrm{TiO}_{2}$ calculated by BET equation are 51.85 and $50.28 \mathrm{~m}^{2} \mathrm{~g}^{-1}$, respectively, and are listed in Table 2. Ag deposited on $\mathrm{TiO}_{2}$ surface did not seem to

Table 1

Average crystalline sizes of photocatalysts of $\mathrm{TiO}_{2}$ and $\mathrm{Ag} / \mathrm{TiO}{ }_{2}$

\begin{tabular}{ll}
\hline Photocatalyst & Average crystalline size $(\mathrm{nm})$ \\
\hline $\mathrm{TiO}_{2}($ Degussa P-25) & 3.302 \\
$\mathrm{Ag} / \mathrm{TiO}_{2}$ & 3.347 \\
\hline
\end{tabular}
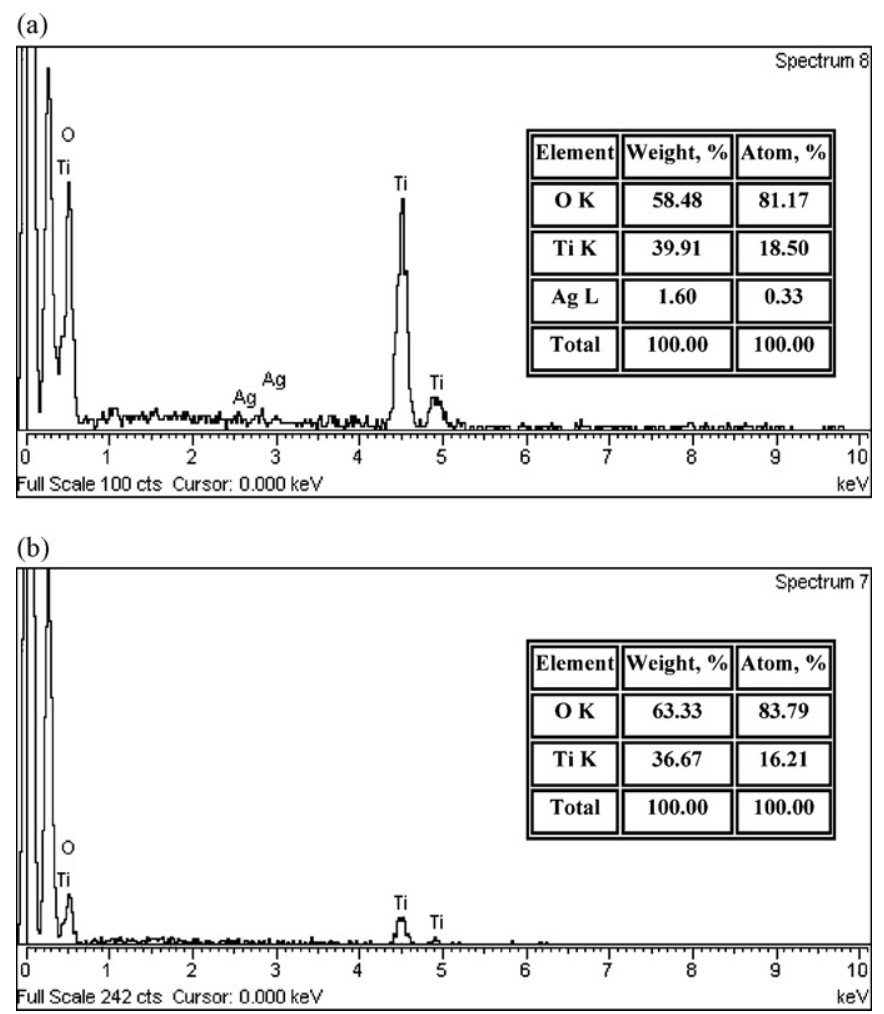

Fig. 5. (a) Diagram of EDS of $\mathrm{Ag} / \mathrm{TiO}_{2}$ particles prepared by impregnation method. Weight percentages of $\mathrm{O}, \mathrm{Ti}$ and $\mathrm{Ag}=58.48,39.91$ and $1.6 \%$. Percentages of atoms of $\mathrm{O}, \mathrm{Ti}$ and $\mathrm{Ag}=81.17,18.50$ and $0.33 \%$. K, L: K, L orbits. (b) Diagram of $\mathrm{EDS}$ of $\mathrm{TiO}_{2}$ particles. Weight percentages of $\mathrm{O}$ and $\mathrm{Ti}=63.33$ and $36.67 \%$. Percentages of atoms of $\mathrm{O}$ and $\mathrm{Ti}=83.79$ and $16.21 \%$. K: K orbit.

change the BET surface area. Luo and Ollis [21] pointed out that the BET surface area of $\mathrm{TiO}_{2}$ is about $50 \mathrm{~m}^{2} \mathrm{~g}^{-1}$ and the $\mathrm{PCO}$ activity mainly depends on the surface area.

\subsection{Reaction rate and influence factors}

\subsubsection{Photolysis of formaldehyde with $U V$}

Prior to the photocatalysis of formaldehyde, a series of tests were conducted to evaluate the decomposition efficiency or conversion $(\eta)$ of formaldehyde by photolysis. $\eta$ is calculated by the following equation:

$\eta(\%)=\frac{C}{C_{0}} \times 100$

where $C_{0}$ is the initial concentration of formaldehyde (ppmv) and $C$ is the concentration of formaldehyde at time $t$ (ppmv).

Table 2

BET surface areas of photocatalysts of $\mathrm{TiO}_{2}$ and $\mathrm{Ag} / \mathrm{TiO}_{2}$

\begin{tabular}{llrll}
\hline Photocatalyst & $\begin{array}{l}\text { Sample } \\
\text { weight }(\mathrm{g})\end{array}$ & $\mathrm{C}^{\mathrm{a}}$ & $\begin{array}{l}V_{\mathrm{m}} \\
\left(\mathrm{cm}^{3} \mathrm{~g}^{-1} \mathrm{STP}\right)^{\mathrm{b}}\end{array}$ & $\begin{array}{l}\text { BET surface } \\
\text { area }\left(\mathrm{m}^{2} \mathrm{~g}^{-1}\right)\end{array}$ \\
\hline $\mathrm{TiO}_{2}$ & 0.4740 & 122.5841 & 11.9100 & 51.85 \\
$\mathrm{Ag} / \mathrm{TiO}_{2}$ & 0.4730 & 98.2034 & 11.5491 & 50.28 \\
\hline
\end{tabular}

\footnotetext{
${ }^{\mathrm{a}}$ BET factor.

b Nitrogen adsorption volume.
} 


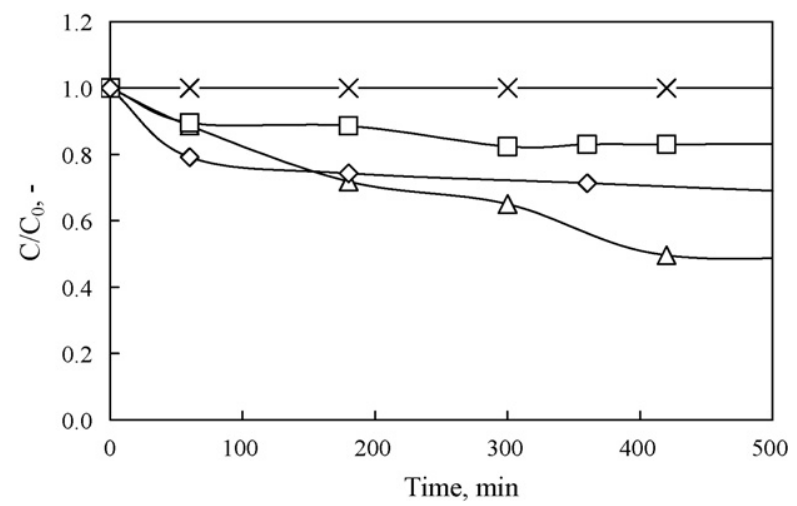

Fig. 6. Time variation of $C / C_{0}$ for the direct photolysis of formaldehyde with different UV light sources: $(\times)$ dark reaction; $(\square) I_{365 \mathrm{~nm}}=1.3 \mathrm{~mW} \mathrm{~cm}^{-2}$; $(\diamond) I_{\mathrm{UVLED}}=0.6 \mathrm{~mW} \mathrm{~cm}^{-2}$ (40 lamps totally); $(\triangle) I_{254 \mathrm{~nm}}=5.5 \mathrm{~mW} \mathrm{~cm}^{-2}$. $C_{0}=500 \mathrm{ppmv}, \quad \mathrm{RH}=50 \%, \quad T=298 \mathrm{~K}, \quad \lambda_{\mathrm{UVLED}}=383 \mathrm{~nm} \quad(\Delta \lambda=18 \mathrm{~nm})$. $P_{254}=16 \mathrm{~W}, P_{365}=12 \mathrm{~W}, P_{\mathrm{UVLED}}=0.8 \mathrm{~W}$ (40 totally). $I$ : light intensity; RH: relative humidity; $P$ : power of light source.

\subsubsection{Photolysis with $U V$ and dark reaction}

The results of dark reaction (with $\mathrm{TiO}_{2}$ coated on glass plates) and photolysis were shown in Fig. 6. After the duration time of $12 \mathrm{~h}$, the adsorption of formaldehyde on $\mathrm{TiO}_{2}$ and degradation of formaldehyde in the dark environment were not detected and can be neglected. The irradiative intensities at the glass plates from UVC, UVA and one UVLED were listed in Table 3. The average irradiative intensities are calculated by the following equation and the distances relative to the light sources are showed in Fig. 7:

$\bar{I}=\left[\frac{2 \pi}{2 \pi\left(r_{1}+r_{2}+r_{3}+r_{4}\right)}\right] \times\left(r_{1} I_{1}+r_{2} I_{2}+r_{3} I_{3}+r_{4} I_{4}\right)$

where $\bar{I}$ is the average illumination intensity $\left(\mathrm{mW} \mathrm{cm}^{-2}\right), r_{i}$ the distance relative to the light source (cm), $i=1$ to 4 , and $I_{i}$ is the irradiative intensity at the distance $r_{i}\left(\mathrm{~mW} \mathrm{~cm}^{-2}\right), i=1$ to 4 .

The average irradiative intensities of light sources are in the order of UVC $\left(6.48 \mathrm{~mW} \mathrm{~cm}^{-2}\right)>\operatorname{UVA}\left(1.57 \mathrm{~mW} \mathrm{~cm}^{-2}\right)>$ one UVLED $\left(0.58 \mathrm{~mW} \mathrm{~cm}^{-2}\right)$. It is reasonable because the powers of the light sources are in the order of UVC $(16 \mathrm{~W})>$ UVA $(12 \mathrm{~W})>$ one UVLED $(20 \mathrm{~mW})$. A photolysis test was conducted by injecting the same concentration of formaldehyde into the reactor without the presence of photocatalysts but with the UV lamp turned on. The direct photolysis of formaldehyde by UVC, UVA lamp and 40-UVLEDs are showed in Fig. 6. The initial

Table 3

Irradiative intensity at various light distances.

\begin{tabular}{llll}
\hline$r$ & \multicolumn{2}{l}{ LS $^{\mathrm{a}}$} & \\
\cline { 2 - 4 } & $365 \mathrm{~nm}$ & $254 \mathrm{~nm}$ & UVLED \\
\hline $1.5 \mathrm{~cm}$ & 2.8 & 11.1 & 0.7 \\
$2 \mathrm{~cm}$ & 1.7 & 7.2 & 0.6 \\
$2.5 \mathrm{~cm}$ & 1.3 & 5.5 & 0.6 \\
$3 \mathrm{~cm}$ & 1.1 & 4.5 & 0.5 \\
Average intensity & 1.57 & 6.48 & 0.58 \\
\hline
\end{tabular}

Unit: $\mathrm{mW} \mathrm{cm}^{-2}$.

${ }^{\text {a }}$ Light source.

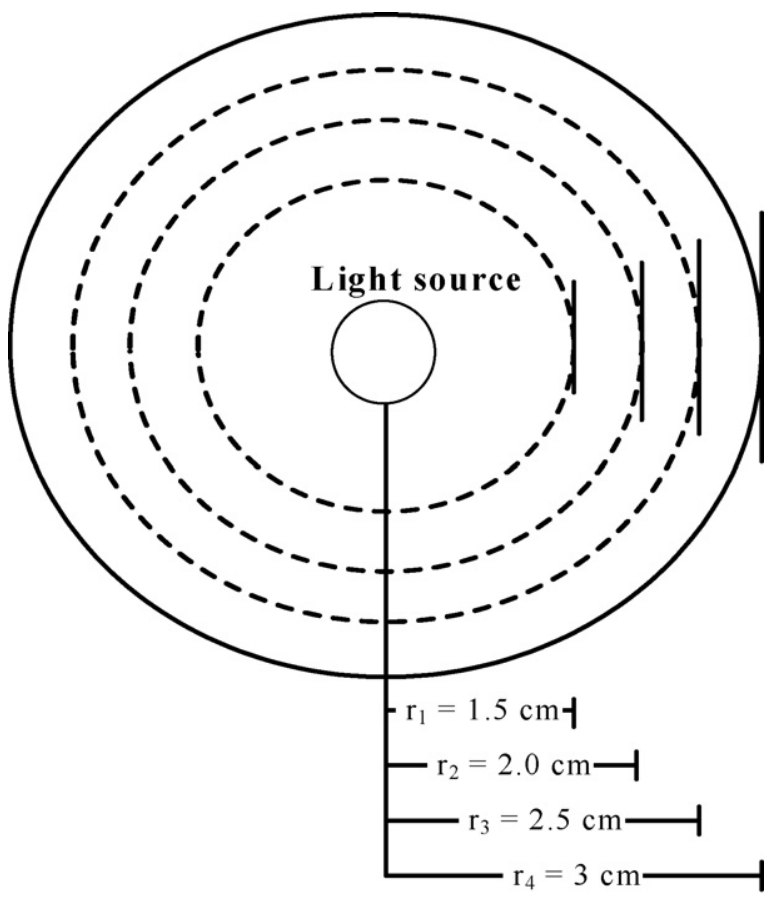

Fig. 7. Position for measuring irradiative intensity.

reaction rates of the three light sources are listed in Table 4. After the illumination on the plates of $2.5 \mathrm{~cm}$ distance of $12 \mathrm{~h}$, the concentrations of formaldehyde for $12 \mathrm{~W}$ UVA, $800 \mathrm{~mW} 40$ UVLEDs ( $20 \mathrm{~mW}$ of one LEDs and 40 totally) and $16 \mathrm{~W}$ UVC lamp were all decreased gradually to a constant values of 83, 66 and $50 \%$, respectively, relative to the initial concentration. As in this study, the UV applied alone was not sufficient without the presence of the photocatalysts for the oxidation of formaldehyde. The UVLED gives a higher $\eta$ than that of UVA maybe due to that the absorption wavelength of formaldehyde is near $\lambda$ of $383 \mathrm{~nm}$ (UVLED). The UVC has the highest $\eta$ maybe due to its highest power among the three light sources. Note that the use of UVC is usually avoided because it is bio-hazardous and not secure to humans.

Table 4

Apparent rate constant $\left(k_{\text {obs }}\right)$ and initial reaction rate $\left(r_{0}\right)$ obtained in the photocatalytic decomposition of formaldehyde with different light sources and catalytic supports $^{\mathrm{a}}$

\begin{tabular}{llllr}
\hline Light source & Photocatalyst & $\begin{array}{l}\text { Catalytic } \\
\text { support }\end{array}$ & $\begin{array}{l}k_{\text {obs }} \\
\left(\mathrm{min}^{-1}\right)\end{array}$ & $\begin{array}{l}r_{0} \\
\left(\mathrm{ppmv} \mathrm{min}^{-1}\right)\end{array}$ \\
\hline UVC & $\mathrm{No}$ & - & 0.0016 & 0.80 \\
UVC & $\mathrm{TiO}_{2}$ & Plates & 0.0223 & 11.15 \\
UVC & $\mathrm{Ag} / \mathrm{TiO}_{2}$ & Plates & 0.0301 & 15.05 \\
UVC & $\mathrm{Ag} / \mathrm{TiO}_{2}$ & Sticks & 0.0557 & 27.85 \\
UVA & $\mathrm{No}$ & - & 0.0005 & 0.25 \\
UVA & $\mathrm{TiO}_{2}$ & Plates & 0.0295 & 14.75 \\
UVA & $\mathrm{Ag} / \mathrm{TiO}_{2}$ & Plates & 0.0333 & 16.65 \\
UVA & $\mathrm{Ag} / \mathrm{TiO}_{2}$ & Sticks & 0.0450 & 22.50 \\
UVLED (30 lamps) & $\mathrm{Ag} / \mathrm{TiO}_{2}$ & Sticks & 0.0121 & 6.05 \\
UVLED (40 lamps) & $\mathrm{No}$ & - & 0.0006 & 0.30 \\
UVLED (40 lamps) & $\mathrm{Ag} / \mathrm{TiO}_{2}$ & Plates & 0.0118 & 5.90 \\
UVLED (40 lamps) & $\mathrm{Ag} / \mathrm{TiO}_{2}$ & Sticks & 0.0146 & 7.30 \\
\hline
\end{tabular}

${ }^{\text {a }} C_{0}=500 \mathrm{ppmv}, \mathrm{RH}=50 \%, T=298 \mathrm{~K}, \lambda_{\mathrm{UVLED}}=383 \mathrm{~nm}(\Delta \lambda=18 \mathrm{~nm})$, cat alysts $=0.05 \mathrm{~g}$ for glass plates and $0.334 \mathrm{~g}$ for glass sticks. 


\subsubsection{Photocatalysis rates of formaldehyde using $\mathrm{TiO}_{2}$ and} $\mathrm{Ag} / \mathrm{TiO}_{2}$ with different light sources coated on glass plates

The apparent rate constant $\left(k_{\text {obs }}\right)$ and initial reaction rate $\left(r_{0}\right)$ of formaldehyde using $\mathrm{TiO}_{2}$ and $\mathrm{Ag} / \mathrm{TiO}_{2}$ with supports of glass plates and sticks are listed in Table 4. The mass of $\mathrm{TiO}_{2}$ and $\mathrm{Ag} / \mathrm{TiO}_{2}$ coated on glass plates was $0.05 \mathrm{~g}$. The $r_{0}$ of UVC $\left(5.5 \mathrm{~mW} \mathrm{~cm}^{-2}\right)$ using $\mathrm{TiO}_{2}$ and $\mathrm{Ag} / \mathrm{TiO}_{2}$ with glass plates are 11.15 and $15.05 \mathrm{ppmv} \mathrm{min}^{-1}$, respectively. Applying UVA $\left(1.3 \mathrm{~mW} \mathrm{~cm}{ }^{-2}\right)$, the $r_{0}$ of $\mathrm{TiO}_{2}$ and $\mathrm{Ag} / \mathrm{TiO}_{2}$ with glass plates are 14.75 and $16.65 \mathrm{ppmv} \mathrm{min}^{-1}$, respectively. The finial $\eta$ of UVC and UVA using $\mathrm{TiO}_{2}$ and $\mathrm{Ag} / \mathrm{TiO}_{2}$ with glass plates are 80 and $82 \%$, and 82 and $86 \%$, respectively. The reason may be due to the absorption wavelength of formaldehyde near $365 \mathrm{~nm}$ and therefore provide enough energy to overcome the energy band gap. In this study, the presence of metallic $\mathrm{Ag}$ does not produce an intrinsic increase in photocatalytic activity in comparison with pure $\mathrm{TiO}_{2}$. However, the slight increase of $\eta$ with $\mathrm{Ag} / \mathrm{TiO}_{2}$ can be explained by the increase of separation efficiency in the electron-hole pair, which is induced by trapping of electrons by metallic $\mathrm{Ag}$ [28]. However, Jin and Shiraishi [30] pointed out that the $r_{0}$ of formaldehyde decomposition of $\mathrm{Pd}-\mathrm{Cu} / \mathrm{TiO}_{2}, \mathrm{Pd} / \mathrm{TiO}_{2}$ and $\mathrm{Pd}-\mathrm{Cu}-\mathrm{Pt} / \mathrm{TiO}_{2}$ are 5.1, 5 and 4.3 times, respectively, larger than that with $\mathrm{TiO}_{2}$ alone. Enhancements in the photocatalytic activities of the $\mathrm{M} / \mathrm{TiO}_{2}$ (M: metallic) may be resulted from the inhibition of a spontaneous recombination between the hole and electron occurring on the surface of excited $\mathrm{TiO}_{2}$ [30] by the metals deposited via photodeposition on the $\mathrm{TiO}_{2}$. Therefore, introduction of the $\mathrm{M} / \mathrm{TiO}_{2}$ photocatalyst to this reactor system is useful to accelerate the oxidative photodecomposition of formaldehyde.

The activity of the photocatalyst depends strongly on the light-illumination (energy per unit area) or the photon flux on the surface of the photocatalyst [27]. The $\eta$ of formaldehyde with UVA, UVC and UVLED (40 totally) at $7 \mathrm{~h}$ with $\mathrm{Ag} / \mathrm{TiO}_{2}$ coated on glass plates are 86,82 , and $65 \%$, respectively. Semiconductors absorb the light with a threshold wavelength that is enough to provide the energy usage to overcome the band gap between valence bands and conduction bands. For $\mathrm{TiO}_{2}$, the UVlight between 300 and $365 \mathrm{~nm}$ wavelength can provide enough energy to overcome the band gap ( 3.23 (anatase) and $3.02 \mathrm{eV}$ (rutile)) [27]. Therefore, the UVA have the higher equilibrium $\eta$ than that of UVC is reasonable. However, the UVLED has the lowest $\eta$ may be due to the lowest illumination intensity. But the tendencies of $\eta$ are similar in the three light sources.

\subsubsection{Photocatalysis rates of formaldehyde with different supports}

Chen et al. [31] first investigated the photocatalytic oxidation of perchloroethylene (PCE) using UVLED over Degussa P-25 $\mathrm{TiO}_{2}$. However, at a UV light power output of only $49 \mathrm{~mW} \mathrm{~cm}^{-2}$, the designed reactor delivers a $\eta$ of PCE of only $43 \%$. In this study, 200 glass sticks were used as supports with $\mathrm{Ag} / \mathrm{TiO}_{2}$ to increase the $\eta$ of formaldehyde using UVC, UVA and UVLED (30 and 40 LEDs) and the results are shown in Fig. 8 and Table 4. The total coated areas and masses of $\mathrm{Ag} / \mathrm{TiO}_{2}$ are $360 \mathrm{~cm}^{2}$ and $0.05 \mathrm{~g}$ on glass plates, and $2355 \mathrm{~cm}^{2}$ (total illuminated areas of the 200 glass sticks) and $0.334 \mathrm{~g}$ on glass sticks, respectively.

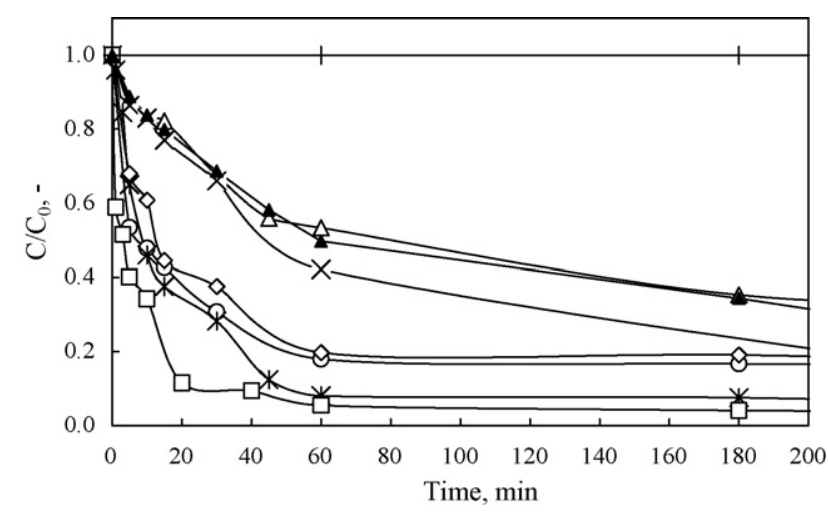

Fig. 8. Time variation of $C / C_{0}$ for the photocatalytic decomposition of formaldehyde using $\mathrm{Ag} / \mathrm{TiO}_{2}$ with different catalytic supports: (+) dark reaction; $(\triangle)$ glass plates $\left(I_{\text {UVLED }}=0.6 \mathrm{~mW} \mathrm{~cm}^{-2}, 40\right.$ lamps $)$;

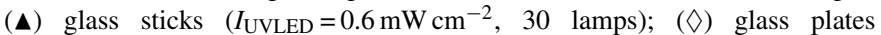
$\left(I_{254 \mathrm{~nm}}=5.5 \mathrm{~mW} \mathrm{~cm}^{-2}\right)$; (○) glass plates $\left(I_{365 \mathrm{~nm}}=1.3 \mathrm{~mW} \mathrm{~cm}^{-2}\right) ; \quad(\times)$ glass sticks $\left(I_{\text {ave, UVLED }}=0.58 \mathrm{~mW} \mathrm{~cm}^{-2}, 40\right.$ lamps $) ; \quad(*)$ glass sticks $\left(I_{\mathrm{ave}}, 365 \mathrm{~nm}=1.57 \mathrm{~mW} \mathrm{~cm}^{-2}\right)$; $(\square)$ glass sticks $\left(I_{\mathrm{ave}}, 254 \mathrm{~nm}=6.48 \mathrm{~mW} \mathrm{~cm}^{-2}\right)$. $C_{0}=500 \mathrm{ppmv}, \quad \mathrm{RH}=50 \%, \quad T=298 \mathrm{~K}, \quad \lambda_{\mathrm{UVLED}}=383 \mathrm{~nm} \quad(\Delta \lambda=18 \mathrm{~nm})$, $P_{254}=16 \mathrm{~W}, P_{365}=12 \mathrm{~W}, P_{\mathrm{UVLED}}=0.6$ (30 totally) and $0.8 \mathrm{~W}$ (40 totally), catalysts $=0.05 \mathrm{~g}$ for glass plates and $0.334 \mathrm{~g}$ for glass sticks. $I$ : light intensity; RH: relative humidity; $P$ : power of light source.

Therefore, the mass per unit area of glass plate and stick are both $0.14 \mathrm{mg} \mathrm{cm}^{-2}$. However, the illuminating area and mass of catalysts on glass sticks are 3.27 and 6.68 times, respectively, to that on glass plates. Therefore, the final $\eta$ at $7 \mathrm{~h}$ of UVC, UVA and 40 UVLEDs with glass sticks and glass plates are $97\left(r_{0}=22.5 \mathrm{ppmv} \mathrm{min}^{-1}\right)$ and $82 \%\left(r_{0}=16.65 \mathrm{ppmv} \mathrm{min}^{-1}\right)$, $96\left(r_{0}=27.85 \mathrm{ppmv} \mathrm{min}^{-1}\right)$ and $86 \%\left(r_{0}=15.05 \mathrm{ppmv} \mathrm{min}^{-1}\right)$,

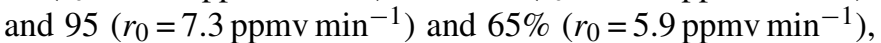
respectively. The $\eta$ and $r_{0}$ of formaldehyde using $\mathrm{Ag} / \mathrm{TiO}_{2}$ coated on glass sticks with different light sources are all higher than those of glass plates because of the increases of illuminated area and mass of $\mathrm{Ag} / \mathrm{TiO}_{2}$. The form of one UVLED is cone radiation, therefore, the distribution of light is in line direction and the illuminating angle is not widely enough. In this study, the UVLEDs were arranged in three lines (one line of 10 LEDs and 30 totally) or four lines (one line of 10 LEDs and 40 totally) in the center of reactor surrounded by the quartz. The illuminating area of UVLEDs is far smaller than that of traditional UV lamp. The effective illuminating area of one UVLED is $1.76 \mathrm{~cm}^{2}$ $(r=2.5 \mathrm{~cm})$, hence, the total effective irradiative areas of 30 and 40 UVLEDs are 52.8 and $70.4 \mathrm{~cm}^{2}$, respectively. The finial $\eta$ and $r_{0}$ of formaldehyde with 30 and 40 UVLEDs at $7 \mathrm{~h}$ are $94 \%$ and $6.05 \mathrm{ppmv} \mathrm{min}^{-1}$, and $95 \%$ and $7.3 \mathrm{ppmv} \mathrm{min}^{-1}$, respectively. The total powers of $30(600 \mathrm{~mW})$ and $40(800 \mathrm{~mW})$ UVLEDs are far lower than those of $16 \mathrm{~W} \mathrm{UVC}$ and $12 \mathrm{~W}$ UVA. The light sources of UVLED (600 and $800 \mathrm{~mW}$ ) can save a lot of energy in comparison with the traditional UV lamps (12 and $16 \mathrm{~W}$ ).

\subsection{Kinetic models of photocatalytic oxidation of formaldehyde with different light sources}

Reaction kinetics gives information about the reaction rates and the mechanisms by which the reactants are converted to the products. The reaction rate can be simply expressed as the rate 


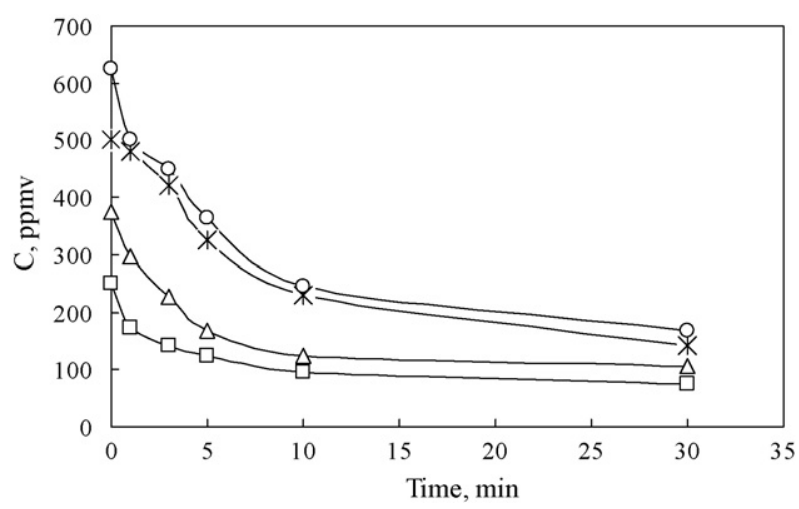

Fig. 9. Photocatalytic degradation of formaldehyde at various initial concentrations $\left(C_{0}\right)$ using $\mathrm{Ag} / \mathrm{TiO}_{2}$ coated on glass sticks: $(\bigcirc) 625 \mathrm{ppmv} ;(\star) 500 \mathrm{ppmv}$; $(\triangle) 375 \mathrm{ppmv}$; $(\square) 250 \mathrm{ppmv}$. RH $=50 \%, T=298 \mathrm{~K}, I_{365 \mathrm{~nm}}=1.57 \mathrm{~mW} \mathrm{~cm}^{-2} . I$ : light intensity; RH: relative humidity; $P$ : power of light source.

law and a common way to express the reaction rate is to use the power law: rate $=-\mathrm{d}[C] / \mathrm{d} t=k[C]^{n}$, where $k$ is the rate constant and $n$ is the order of the reaction. In general, first- and secondorder models are more common [32]. PCO of formaldehyde can be simulated by using pseudo-first-order rate reaction [33]. This study addressed kinetic models of PCO of formaldehyde with different light sources. Taking light source of UVA for example, Fig. 9 shows the photocatalytic degradation of formaldehyde at various initial concentrations $\left(C_{0}\right)$ using $\mathrm{Ag} / \mathrm{TiO}_{2}$ coated on glass sticks with UVA. The PCO of formaldehyde in air is a pseudo-first-order reaction [33], yielding

$-\frac{\mathrm{d} C}{\mathrm{~d} t}=k_{\mathrm{obs}} C$

where $C$ is the concentration of formaldehyde and $k_{\text {obs }}$ is the apparent rate constant of formaldehyde under photocatalytic oxidation in air $\left(\mathrm{min}^{-1}\right)$.

In terms of conversion of formaldehyde $\left(X, X=\left(C_{0}-C\right) / C_{0}\right)$, Eq. (3) becomes

$r=\frac{\mathrm{d} X}{\mathrm{~d} t}=-\frac{\mathrm{d}\left(C / C_{0}\right)}{\mathrm{d} t}=k_{\mathrm{obs}}(1-X)=k_{\mathrm{obs}}\left(\frac{C}{C_{0}}\right)$

Integrates Eq. (4), yielding

$-\ln \left(\frac{C}{C_{0}}\right)=k_{\mathrm{obs}} t$

The slope of the plot of $-\ln \left(C / C_{0}\right)$ versus $t$ at various initial concentration $\left(C_{0}\right)$ is $k_{\mathrm{obs}}$ and $r_{0}$ is the value of $k_{\mathrm{obs}} \times C_{0}$. Table 4 illustrates $k_{\mathrm{obs}}$ and $r_{0}$ obtained in the photocatalytic decomposition of formaldehyde using different light sources and catalytic supports. Table 5 lists $k_{\text {obs }}$ and $r_{0}$ at various $C_{0}$ of formaldehyde using $\mathrm{Ag} / \mathrm{TiO}_{2}$ coated on glass sticks with UVA.

The kinetic models of the PCO process are essential to the optimization of experimental conditions and subsequently, to the design of large-scale photocatalytic reactors. Several kinetic models have been developed, also, the degradation rate expressions have been focused on $r_{0}$ of formaldehyde or the initial formation rate of $\mathrm{CO}_{2}$. The equilibration time for the adsorption of formaldehyde and dissolved oxygen without light illumination is an important variable, especially for the determination
Table 5

Pseudo-first-order reaction rate constants $\left(k_{\mathrm{obs}}\right)$ and initial reaction rates $\left(r_{0}\right)$ at various initial concentrations $\left(C_{0}\right)$ of formaldehyde using $\mathrm{Ag} / \mathrm{TiO}_{2}$ coated on glass sticks with UVA

\begin{tabular}{lll}
\hline$C_{0}(\mathrm{ppmv})$ & $k_{\mathrm{obs}}\left(\mathrm{min}^{-1}\right)$ & $r_{0}\left(\mathrm{ppmv} \mathrm{min}^{-1}\right)$ \\
\hline 250 & 0.0500 & 12.50 \\
375 & 0.0530 & 19.88 \\
500 & 0.0450 & 22.50 \\
625 & 0.0509 & 31.81 \\
\hline
\end{tabular}

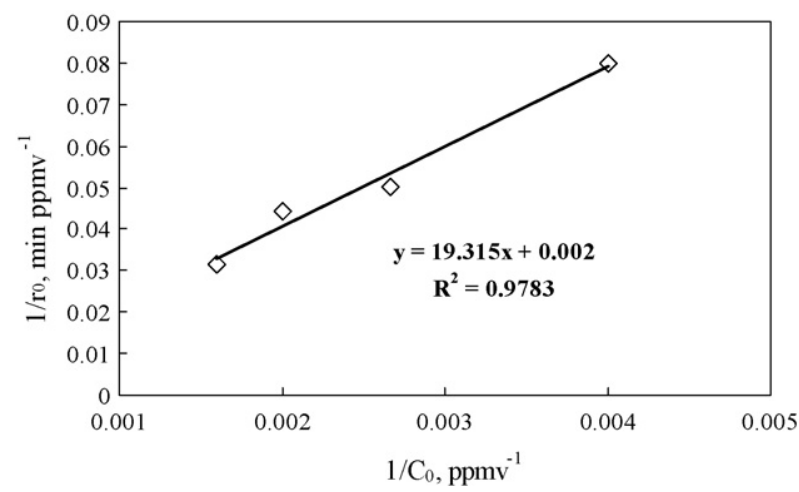

Fig. 10. Langmuir-Hinshelwood plot of $1 / r_{0}$ vs. $1 / C_{0}$ of formaldehyde using $\mathrm{Ag} / \mathrm{TiO}_{2}$ coated on glass sticks. $r_{0}, C_{0}$ : initial reaction rate and concentration. $\mathrm{RH}=50 \%, T=298 \mathrm{~K}, I_{365 \mathrm{~nm}}=1.57 \mathrm{~mW} \mathrm{~cm}^{-2}$.

of $r_{0}$ [34]. The Langmuir-Hinshelwood model has been widely used to formulate the rate equations for the PCO reaction. The model uses Eq. (6) to determine the disappearance rate $(r)$ of formaldehyde:

$r_{0}=-\frac{\mathrm{d} C_{0}}{\mathrm{~d} t}=k_{\mathrm{obs}} C_{0}=\frac{k K_{\mathrm{L}} C_{0}}{1+K_{\mathrm{L}} C_{0}}$

where $k$ is the reaction rate constant and $K_{\mathrm{L}}$ is the adsorption equilibrium constant $\left(k_{\mathrm{obs}}=k K_{\mathrm{L}} /\left(1+K_{\mathrm{L}} C_{0}\right)\right)$. The reciprocal of reverse Eq. (6) yields:

$\frac{1}{r_{0}}=\frac{1}{k_{\mathrm{obs}} C_{0}}=\frac{1}{k}+\frac{1}{k K_{\mathrm{L}}} \times \frac{1}{C_{0}}$

Fig. 10 illustrates the plot of $1 / r_{0}$ versus $1 / C_{0}$ at various $C_{0}$ for the $\mathrm{PCO}$ of formaldehyde over $\mathrm{Ag} / \mathrm{TiO}_{2}$ coated on glass sticks with UVA. The slope and intercept are $0.002\left(k^{-1}\right)$ and 19.315 $\left(k K_{\mathrm{L}}\right)^{-1}$, respectively, and $R^{2}$ is 0.9783 . Therefore, $k$ and $K_{\mathrm{L}}$ are $500 \mathrm{ppmv} \mathrm{min}^{-1}$ and $1.04 \times 10^{-4} \mathrm{ppmv}^{-1}$, respectively, and listed in Table 6. Using the same method, $k$ and $K_{\mathrm{L}}$ over $\mathrm{Ag} / \mathrm{TiO}{ }_{2}$ coated on glass sticks with $12 \mathrm{~W}$ UVC and $800 \mathrm{~mW}$ UVLED are also listed in Table 6 . A comparison of the simulation results

Table 6

Reaction rate constant $(k)$ and adsorption equilibrium constant $\left(K_{\mathrm{L}}\right)$ for the photocatalytic decomposition of formaldehyde using $\mathrm{Ag} / \mathrm{TiO}_{2}$ in $\mathrm{UV}$ light reaction system

\begin{tabular}{lll}
\hline Light source & $k\left(\mathrm{ppmv} \mathrm{min}^{-1}\right)$ & $K_{\mathrm{L}}\left(\mathrm{ppmv}^{-1}\right)$ \\
\hline UVA & 500 & $1.04 \times 10^{-4}$ \\
UVC & 650 & $2.00 \times 10^{-4}$ \\
40 UVLEDs & 600 & $2.52 \times 10^{-5}$
\end{tabular}




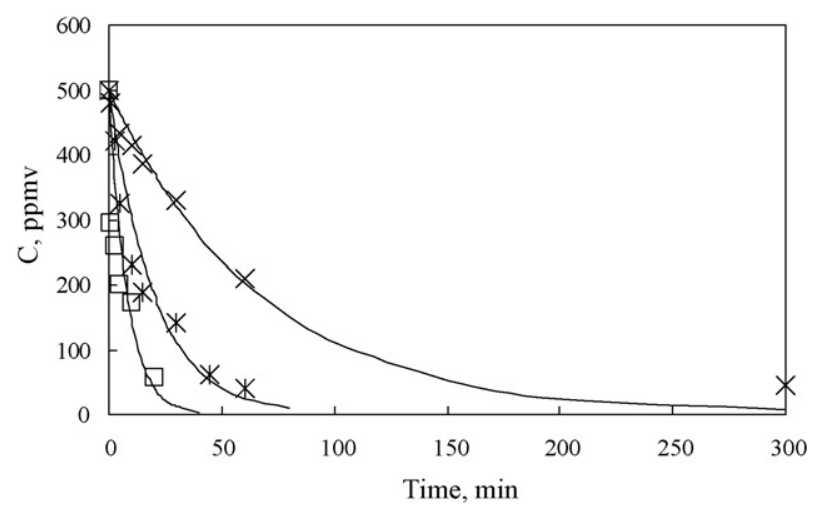

Fig. 11. Variation of $C / C_{0}$ with time for the photocatalytic decomposition of formaldehyde: $(\times)$ glass sticks $\left(I_{\text {ave, }}\right.$ UVLED $=800 \mathrm{~mW}, 40$ LED totally); $(\star)$ glass sticks $\left(I_{\mathrm{ave}}, 365 \mathrm{~nm}=12 \mathrm{~W}\right) ;(\square)$ glass sticks $\left(I_{\mathrm{ave}}, 254 \mathrm{~nm}=16 \mathrm{~W}\right) .\left(C_{0}=500 \mathrm{ppmv}\right.$; $\left.\mathrm{RH}=50 \% ; T=303 \mathrm{~K} ; \lambda_{\mathrm{UVLED}}=383 \mathrm{~nm}(\Delta \lambda=18 \mathrm{~nm})\right)$. Line: computed by a best fit. Symbol: experimental.

using the proposed Langmuir-Hinshelwood kinetic models with the experimental data was also made and illustrated in Fig. 11, indicating good agreement.

\subsection{Decomposition efficiency $(\eta)$ versus energy effectiveness $\left(E_{e}\right)$}

In order to compare the power consumption versus decomposition efficiency of different light sources, the energy effectiveness $\left(E_{\mathrm{e}}\right)$ is calculated by the following equation:

Energy effectiveness $\left(E_{\mathrm{e}}, \mathrm{mg} \mathrm{kW}^{-1} \mathrm{~h}^{-1}\right)$

$=$ decomposition mass of formaldehyde $(\mathrm{mg}) /$ input power $(\mathrm{kW} \mathrm{h})$

$$
=\frac{\left[\left(C_{0}-C\right) \times 10^{-3} \times M \times P V / R T\right]}{w \times t}
$$

where $C_{0}$ is the initial concentration of formaldehyde (ppmv), $C$ the concentration of formaldehyde at time $t$ (ppmv), $M$ the molecular mass of formaldehyde $\left(\mathrm{g} \mathrm{mol}^{-1}\right), P$ the atmospheric pressure (atm), $V$ the volume of reactor (L), $R$ the universal gas constant $\left(0.082 \mathrm{~atm} \mathrm{~L} \mathrm{~mol}{ }^{-1} \mathrm{~K}^{-1}\right), T$ the absolute temperature $(\mathrm{K}), w$ the power of consumption $(\mathrm{kW})$, and $t$ is the reaction time (h).

Table 7 lists the $\eta$ and energy effectiveness $\left(E_{\mathrm{e}}\right)$ for the photocatalytic decomposition of formaldehyde using $\mathrm{Ag} / \mathrm{TiO}_{2}$ in different UV light sources. At the reaction time of $7 \mathrm{~h}$, the magnitudes of energy effectiveness $\left(E_{\mathrm{e}}\right)$ of different light sources are in the order

Table 7

Decomposition efficiency $\left(\eta_{\mathrm{D}}\right)$ and energy effectiveness $\left(E_{\mathrm{e}}\right)$ for the photocatalytic decomposition of formaldehyde using $\mathrm{Ag} / \mathrm{TiO}_{2}$ in $\mathrm{UV}$ light reaction system

\begin{tabular}{llll}
\hline Light source & $\eta_{\mathrm{D}}(\%)$ & Reaction time $(\mathrm{h})$ & $E_{\mathrm{e}}\left(\mathrm{mg} \mathrm{kW}^{-1} \mathrm{~h}^{-1}\right)$ \\
\hline 40 UVLEDs & 95 & 7 & 0.6942 \\
UVA & 96 & 7 & 0.0070 \\
UVC & 97 & 7 & 0.0053 \\
\hline
\end{tabular}

of $800 \mathrm{~mW}$ UVLED $\left(0.6942 \mathrm{mg} \mathrm{kW}^{-1} \mathrm{~h}^{-1}\right)>16 \mathrm{~W} \quad$ UVA $\left(0.007 \mathrm{mg} \mathrm{kW}^{-1} \mathrm{~h}^{-1}\right)>12 \mathrm{~W}$ UVC $\left(0.0053 \mathrm{mg} \mathrm{kW}^{-1} \mathrm{~h}^{-1}\right)$. The $E_{\mathrm{e}}$ of UVLED is 131 times larger than that of UVC. In the near future, the fossil energy will be nearly exhausted and the new technology that can save energy will be encouraged.

\section{Conclusions}

This study investigated the surface modification of photocatalyst and photodecomposition of volatile organic compounds (VOCs) from indoor pollution source. Formaldehyde was taken as a model compound. The photocatalyst of $\mathrm{Ag} / \mathrm{TiO}_{2}$ was made by the impregnation method. The XRD, SEM and BET surface were used for characterizing $\mathrm{Ag} / \mathrm{TiO}_{2}$. Regarding the light sources, this study explored the feasibility of the application of the UVLED instead of the traditional UV lamp to treat the formaldehyde. Furthermore, this study also proposed the photocatalytic kinetic models. The photocatalytic decomposition of formaldehyde at various initial concentrations was elucidated according to the Langmuir-Hinshelwood model. A comparison of the simulation results using the proposed Langmuir-Hinshelwood kinetic models with the experimental data was also made, indicating good agreement. The light sources of UVLED (600 and $800 \mathrm{~mW}$ ) can save a lot of energy in comparison with the traditional UV lamps (12 and $16 \mathrm{~W}$ ). Using UVLED light as light source can enhance not only the safety with less UV intensity but also the energy usage efficiency. Thus, this study showed the feasible and potential use of UVLED in photocatalysis.

\section{Acknowledgement}

We express our sincere thanks to the National Science Council of Taiwan for the financial support, under the contract number NSC 94-2211-E-197-002.

\section{References}

[1] C.H. Ao, S.C. Lee, J.Z. Yu, J.H. Xu, Photodegradation of formaldehyde by photocatalyst $\mathrm{TiO}_{2}$ : effects on the presences of $\mathrm{NO}, \mathrm{SO}_{2}$ and VOCs, Appl. Catal. B: Environ. 54 (2004) 41-50.

[2] S.B. Kim, S.C. Hong, Characteristics of low-temperature annealed $\mathrm{TiO}_{2}$ films deposited by precipitation from hydrolyzed $\mathrm{TiCl}_{4}$ solutions, Appl. Catal. B: Environ. 35 (2002) 305-315.

[3] J.M. Peralta-Hernández, J. Manríquez, Y. Meas-Vong, F.J. Rodríguez, T.W. Chapman, M.I. Maldonado, L.A. Godínez, Photocatalytic properties of nano-structured $\mathrm{TiO}_{2}$-carbon films obtained by means of electrophoretic deposition, J. Hazard. Mater. 147 (2007) 588-593.

[4] M.M. Ameen, G.B. Raupp, Reversible catalyst deactivation in the photocatalytic oxidation of diluteo-xylene in air, J. Catal. 184 (1999) 112-122.

[5] G.L. Puma, P.L. Yue, A novel fountain photocatalytic reactor: model development and experimental validation, Chem. Eng. Sci. 56 (2001) 2733-2744.

[6] J.H. Mo, Y.P. Zhang, R. Yang, Novel insight into VOC removal performance of photocatalytic oxidation reactors, Indoor Air 15 (2005) 291-300.

[7] R. Yang, Y.P. Zhang, Q.J. Xu, A mass transfer based method for measuring the reaction coefficients of a photocatalyst, Atmos. Environ. 41 (2007) $1221-1229$.

[8] H. Einaga, S. Futamura, T. Ibusuki, Heterogeneous photocatalytic oxidation of benzene, toluene, cyclohexene and cyclohexane in humidified air: 
comparison of decomposition behavior on photoirradiated $\mathrm{TiO}_{2}$ catalyst, Appl. Catal. B: Environ. 38 (2002) 215-225.

[9] Y.P. Zhang, R. Yang, Q.J. Xu, Characteristics of photocatalytic oxidation of toluene, benzene and their mixture, J. Air Waste Manage. 57 (2007) 94-101.

[10] J. Peral, D.F. Ollis, Heterogeneous photocatalytic oxidation of gasphase organics from air purification: acetone, 1-butanol, butyraldehyde, formaldehyde, and $m$-xylene oxidation, J. Catal. 136 (1992) 554-565.

[11] T. Noguchi, A. Fujishima, P. Sawunyama, K. Hashimoto, Photocatalytic degradation of gaseous formaldehyde using $\mathrm{TiO}_{2}$ film, Environ. Sci. Technol. 32 (1998) 3831-3833.

[12] D. Norbäck, G. Wieslander, C. Edling, Occupational exposure to volatile organic compounds (VOCs), and other air pollutants from the indoor application of water-based paints, Ann. Occup. Hyg. 39 (1995) 783-794.

[13] S.C. Lee, B. Wang, Characteristics of emissions of air pollutants from burning of incense in a large environmental chamber, Atmos. Environ. 38 (2004) 941-951.

[14] T.N. Obee, R.T. Brown, $\mathrm{TiO}_{2}$ photocatalysis for indoor air applications: effects of humidity and trace contaminant levels on the oxidation rates of formaldehyde, toluene, and 1,3-butadiene, Environ. Sci. Technol. 29 (1995) 1223-1231.

[15] F. Shiraishi, S. Yamaguchi, Y. Ohbuchi, A rapid treatment of formaldehyde in a highly tight room using a photocatalytic reactor combined with a continuous adsorption and desorption apparatus, Chem. Eng. Sci. 58 (2003) 929-934.

[16] H. Ichiura, T. Kitaoka, H. Tanaka, Removal of indoor pollutants under UV irradiation by $\mathrm{A}$ composite $\mathrm{TiO}_{2}$-zeolite sheet prepared using A papermaking technique, Chemosphere 50 (2003) 79-83.

[17] C. Zhang, H. He, K. Tanaka, Perfect catalytic oxidation of formaldehyde over a $\mathrm{Pt} / \mathrm{TiO}_{2}$ catalyst at room temperature, Catal. Commun. 6 (2005) 211-214.

[18] M.L. Sauer, D.F. Ollis, Acetone oxidation in a photocatalytic monolith reactor, J. Catal. 149 (1994) 81-91.

[19] D. Hennezel, O.P. Pichat, D.F. Ollis, Benzene and toluene gas-phase photocatalytic degradation over $\mathrm{H}_{2} \mathrm{O}$ and $\mathrm{HCl}$ pretreated $\mathrm{TiO}_{2}$ : by-products and mechanisms, J. Photochem. Photobiol. A: Chem. 118 (1998) 197-204.

[20] D. Chen, A.K. Ray, Photocatalytic kinetics of phenol and its derivatives over UV irradiated $\mathrm{TiO}_{2}$, Appl. Catal. B: Environ. 23 (1999) 143-157.
[21] Y. Luo, D.F. Ollis, Heterogeneous photocatalytic oxidation of trichloroethylene and toluene mixtures in air: kinetic promotion and inhibition, time-dependent catalyst activity, J. Catal. 163 (1996) 1-11.

[22] T.N. Obee, S.O. Hay, Effects of moisture and temperature on the photooxidation of ethylene on titania, Environ. Sci. Technol. 31 (1997) 20342038.

[23] J.A. Dibble, G.B. Raupp, Fluidized-bed photocatalytic oxidation of trichloroethylene in contaminated air streams, Environ. Sci. Technol. 26 (1992) 492-495.

[24] L. Cao, Gas-phase oxidation of 1-butene using nanoscale $\mathrm{TiO}_{2}$ photocatalysts, J. Catal. 188 (1999) 48-57.

[25] T.H. Lim, S.M. Jeong, S.D. Kim, J. Gyenis, Photocatalytic decomposition of $\mathrm{NO}$ by $\mathrm{TiO}_{2}$ particles, J. Photochem. Photobiol. A: Chem. 134 (2000) 209-217.

[26] S.A. Larson, J.A. Widegren, J.L. Falconer, Transient studies of 2-propanol photocatalytic oxidation on titania, J. Catal. 157 (1995) 611-625.

[27] J. Zhao, X. Yang, Photocatalytic oxidation for indoor air purification: a literature review, Build. Environ. 38 (2003) 645-654.

[28] J.M. Herrmann, H. Tahiri, Y. Ait-Ichou, G. Lassaletta, A.R. GonzálezElipe, A. Fernández, Characterization and photocatalytic activity in aqueous medium of $\mathrm{TiO}_{2}$ and $\mathrm{Ag}-\mathrm{TiO}_{2}$ coatings on quartz, Appl. Catal. B: Environ. 13 (1997) 219-228.

[29] J.H. Sclafani, J. Herrmann, Comparison of the photoelectronic and photocatalytic activities of various anatase and rutile forms of titania in pure liquid organic phases and in aqueous solutions, J. Phys. Chem. 100 (1996) 13655-13661.

[30] S. Jin, F. Shiraishi, Photocatalytic activities enhanced for decompositions of organic compounds over metal-photodepositing titanium dioxide, Chem. Eng. J. 97 (2004) 203-211

[31] D.H. Chen, X.J. Ye, K.Y. Li, Oxidation of PCE with a UV LED photocatalytic reactor, Chem. Eng. Technol. 28 (2005) 95-97.

[32] J.I. Steinfeld, J.S. Francisco, W.L. Hase, Chemical Kinetics and Dynamics, Prentice-Hall Inc., Englewood Cliffs, NJ, 1998, pp. 1-198.

[33] W.H. Ching, M. Leung, Y.C. Leung, Solar photocatalytic degradation of gaseous formaldehyde by sol-gel $\mathrm{TiO}_{2}$ thin film for enhancement of indoor air quality, Sol. Energ. 77 (2004) 129-135.

[34] M.R. Hoffman, S.T. Martin, W. Choi, D.W. Bahnemann, Environmenta applications of semiconductor photocatalysis, Chem. Rev. 95 (1995) 69-96. 